\title{
CROSS FERTILIZATION: UM DIRECIONAMENTO PARA A INOVAÇÃO
}

Patrícia de Mello Souza

Universidade Estadual de Londrina-UEL

patriciademellosouza@gmail.com

Giovanni Maria Conti

Politecnico di Milano

giovanni.conti@polimi.it

Resumo: $O$ artigo discute a dinâmica da cross fertilization, que remete ao contexto das relações de contiguidade entre diferentes áreas do conhecimento. Identificam-se princípios condutores comuns que direcionam o pensamento projetual, bem como elementos que agem como ativadores de transferências de conhecimento e facilitadores de processos de geração inovativos. O argumento abordado no decorrer do estudo comprova, mediante a análise das relações que se estabelecem entre os distintos setores, que é dentro das zonas de fronteira - aquele campo de intersecção que pode ser gerado entre uma área disciplinar e outra, que de fato são ativadas as dinâmicas que facilitam o surgimento de processos de inovação significativos.

Palavras-chave: design, moda, arquitetura, cross fertilization, inovação.

Abstract: The article deals with the product development process guided by the dynamics of the cross-fertilization, which leads to the context of contiguity relations between different areas of knowledge. Principles common conductors are identified to drive architectural design thinking as well as elements that act as enablers of knowledge transfer and facilitators of innovative generation processes. The argument discussed in the course of this study proves, by analyzing the relationships established between the different sectors that is within the border areas - that intersection field that can be generated from a subject area to another, which in fact activates the dynamics that facilitate the emergence of significant innovation processes.

Keywords: design, fashion, architecture, cross fertilization, innovation. 


\section{INTRODUÇÃO}

$\mathrm{Na}$ contemporaneidade, os processos de transferência entre setores mercadológicos diversos como os de vestuário, calçados, acessórios, têxteis para mobiliário, entre outros, representam dinâmicas já consolidadas em determinados cenários. Considera-se que o projeto dedicado aos distintos segmentos e ao sistema que é gerado em seu entorno é pensado de forma transversal, inserido no contexto dos fenômenos culturais, produtivos, midiáticos e consumistas. Isto significa que não basta elaborar o que se pretende mas analisar os processos que geram a intenção desta criação. Seria redutivo limitar-se à dimensão industrial e considerar o produto acabado como o único resultado deste desenvolvimento.

A moda, o design e a arquitetura pertencem à ampla cultura do projeto onde se desenvolvem cenários complexos que consideram os objetos, os sistemas e os sinais que regulam as relações entre os seres humanos e seus contextos. Assim, qualquer atividade projetual participante desta cultura opera para que a realização de produtos, sejam eles físicos ou intangíveis, contemplem a história, a evolução e as mudanças da sociedade para a obtenção de resultados inovadores.

Segundo Souza (2013), o diálogo entre os campos do conhecimento como forma de apropriação de novos conceitos, técnicas e aquisição de competências além daquelas pertinentes à própria área poderá contribuir para gerar inovação. Neste sentido, Conti (2008) afirma que a área de pesquisa do design e da moda, entendidos como projetos de objetos para o corpo, vem a ser um dos setores projetuais nos quais se pode articular processos de inovação que, conduzidos pela dinâmica definida como cross fertilization envolvem a troca de saberes e de competências entre os diversos âmbitos.

Adota-se o termo, para indicar um fenômeno de interdisciplinaridade ou relação de contiguidade entre as diferentes áreas do conhecimento humano; não diz respeito a uma determinada área específica mas sim à fronteira, a zona de pesquisa que é gerada entre um domínio e outro. Conti (2007) esclarece que o conceito foi introduzido pelo matemático James Clerk Maxwell, em 1878, e consiste na possibilidade de adotar inovações já experimentadas em campos distintos dando lugar a transferência de conhecimento entre setores. A sua aplicação como instrumento condutor de projeto no campo do design, tem demonstrado que esta transferência pode se manifestar de modo implícito - no caso de sentido ou significado que se transporta de uma entidade para outra; e de modo explicito - quando se trata de transferência de tecnologia, de fabricação ou de processo industrial que caracteriza um setor ou parte dele.

Neste contexto, o presente artigo discute processos orientados pela dinâmica da cross fertilization. Inicialmente abordam-se as interações projetuais e os aspectos ou elementos que podem agir como ativadores das dinâmicas de transferência de conhecimentos entre as áreas; na sequência, identificam-se princípios comuns que direcionam o pensamento para projetar a arquitetura, o design ou a moda; finalmente nos relatos do workshops acadêmicos, apresentam-se casos práticos de aplicação da cross fertilization no desenvolvimento de produtos. 


\section{DESENVOLVIMENTO}

Determinados elementos, ações ou posicionamentos podem funcionar como ativadores das dinâmicas de transferência de conhecimentos entre as áreas, para facilitar o surgimento de processos de inovação significativos.

Para Souza (2014), o projetista contemporâneo se apropria de conceitos e estruturas advindos de campos distintos e enfatiza a oportunidade de pensar sobre uma nova construção a partir de elementos que não fazem parte do próprio universo. Trata-se de uma forma de responder as necessidades atuais e de contemplar mudanças sociais e ambientais.

No contexto de um cenário híbrido, fragmentado e adaptativo, moda e arquitetura coexistem e se desenvolvem mutuamente de modo a garantir que os espaços não sejam delineados exclusivamente por princípios geométricos mas que extrapolem o limite das estruturas físicas.

Refletir a moda e a arquitetura sob a ótica do habitar é compreendê-las a partir das vivências. A face interna de uma vestimenta, afirma Quinn (2009), pode ser vista como uma superfície que revela um vazio em sua interioridade, isto é, um espaço interno a ser habitado pelo corpo. Ali, uma multiplicidade de cavidades é formada pela aderência e pelas camadas de construção do produto. No corpo do usuário, percebe-se um ciclo de transferência constante deste espaço, ocasionado pela fusão entre o corpo e a roupa. As experiências corporais, interações entre o corpo habitante e o espaço habitado possibilitam, portanto, a percepção dos limites físicos caracterizados por estas relações na forma de roupas ou de ambientes construídos.

O espaço, experienciado e partilhado pelas áreas, constitui-se objeto de planejamento do design e da arquitetura e como tal deve ser projetado, a fim de promover a adequação dos habitats aos seus usuários.

As indicações presentes no conjunto padrão de um projeto arquitetônico plantas, seções, elevações, bem como desenho de detalhes - são também encontrados nos moldes de produtos do vestuário, afirma Hodge (2007). Nestes, dispositivos gráficos sinalizam a colocação de costuras, piques, e meios de fixação, além das formas dos vários componentes que são cortados e montados em um produto acabado.

De modo similar, arquitetos desenvolvem plantas para mostrar a disposição dos vários compartimentos de uma edificação. Para Mello (2010), por vezes, as representações gráficas bidimensionais dos produtos de arquitetura e de moda apresentam traços projetuais tão semelhantes, que dificulta a sua identificação de forma imediata, a ponto de confundir moldes do vestuário com cartas topográficas ou com mapas territoriais e urbanos.

Souza (2006) afirma, que tanto a conformação da vestimenta, quanto a construção de um edifício, estão atreladas à natureza dos materiais utilizados e às soluções estruturais que permitem, definindo o modo como se articulam ao redor do corpo que ali habita.

Suas escalas de produção são diferentes, adverte Hodge (2007): designers de moda criam vestuário para corpos humanos, enquanto arquitetos criam edifícios 
suficientemente grandes para muitos corpos habitarem simultaneamente. Independente da escala, contudo, o ponto de origem das práticas é o corpo.

Os profissionais dessas áreas desenvolvem muitos estudos sobre as mesmas questões: a espacialidade, a ergonomia, a forma, a função, as técnicas construtivas, entre tantas outras. Influenciados pelos mesmos cânones, comunicam-se por meio de uma linguagem estética semelhante, compartilham fundamentos ideológicos e teóricos, e convivem com as inovações tecnológicas - aspectos que se refletem nas vestimentas e nas edificações.

Observam-se pontos congruentes entre a concepção de produtos de moda e o projeto arquitetônico, confirmam Geisel e Souza (2012). Aspectos relevantes para o desenvolvimento de edificações, tais como: as necessidades dos habitantes com relação à construção, as condições do terreno e o entorno, podem ser - na moda, comparados à importância de conhecer o corpo do usuário, suas demandas e o meio no qual se insere.

O conforto é uma rede de inter-relacionamento que se conecta com as características do sujeito, do objeto e do ambiente, em determinado contexto (SILVA, 2010). Para desenvolver um projeto arquitetônico que atente para o conforto térmico do usuário, alguns aspectos devem ser observados, como a orientação quanto à insolação, o aproveitamento da ventilação natural e o sombreamento da fachada, entre outros.

Torna-se possível também, importar o conceito de conforto térmico da arquitetura para o campo da moda, estabelecendo um diálogo entre os dois campos do saber. A arquitetura é responsável pela criação de espaços confortáveis, assim como a moda é responsável pelo conforto do usuário na sua relação com o traje. Neste sentido, justifica-se o paralelo estabelecido entre as estruturas arquitetônicas que garantem o conforto térmico nas edificações e os recursos empregados na construção do produto do vestuário de moda que interferem diretamente no conforto térmico do usuário.

O conforto trata da comodidade e do bem-estar: considerando que a vestimenta é o primeiro habitat do corpo - como uma segunda pele - ela afeta diretamente a qualidade e o modo de vida do usuário, interferindo nas suas sensações e percepções (SOUZA, 2006). A arquitetura busca a harmonização das construções ao clima e às características locais, transformando os espaços construídos em espaços confortáveis, utilizando-se de recursos que favoreçam a iluminação e ventilação naturais.

Recentes alianças da moda com a tecnologia e a segurança imbuem as roupas do contemporâneo com muitos dos sistemas característicos dos ambientes arquitetônicos. Projetadas para fornecer ao usuário um sentido de refúgio e um grau de proteção contra a violência urbana, conferem maior funcionalidade por meio dos materiais e dispositivos tecnológicos e ampliam a mobilidade do corpo, na medida em que permitem a interação com seus sistemas (QUINN, 2009).

Por outro lado, os espaços infláveis - estruturas itinerantes que podem ser montadas e desmontadas com grande rapidez, tendo suas dimensões 
consideravelmente reduzidas - tem revelado o potencial da arquitetura para se tornar móvel e portátil, estabelecendo grande similaridade com produtos do vestuário.

Promove-se, portanto, a aproximação entre edifícios e produtos do vestuário, para que ambos possam ser concebidos como séries de estruturas permanentes e habitações portáteis. Assim como os designers usam materiais macios e métodos de costura para projetar abrigos portáteis, arquitetos implantam técnicas semelhantes para promover novas redes estruturais e edifícios móveis.

Quando se adota o compartilhamento de técnicas, percebe-se que a construção tradicional de alvenaria muitas vezes é substituída por práticas que envolvem o tecer e o trançar, dando origem a edifícios que têm mais em comum com uma peça do vestuário do que com a arquitetura convencional, pois as estruturas têxteis tecem dentro e fora do espaço público. Carbono, fibra de vidro, e uma gama de fibras naturais e materiais sustentáveis podem ser trançados em estruturas maleáveis e resistentes.

Para Hodge (2007) e Quinn (2009), os arquitetos Peter Testa e Devyn Weiser realizam pesquisas nesta área e são pioneiros nos projetos para construção de grandes edifícios com o entrançamento de fibras de carbono. Os autores confirmam que quando fibras e cordões poliméricos flexíveis são torcidos ou agrupados em cabos e trançados, criam um mecanismo que distribui uniformemente a carga e geram estruturas que podem ser mais eficientes do que a alvenaria, tornando a construção altamente resistente ao impacto.

Assim, a exemplo da relação conceitual que se estabelece entre construir para morar, e confeccionar para vestir, tantas outras se revelam como possibilidades, traçando zonas de fronteira entre áreas distintas que permitem vislumbrar uma trajetória de inovação.

Partindo-se do princípio de que o desenvolvimento projetual permite estabelecer uma troca contínua e um diálogo constante entre conhecimentos diversos, uma vez delimitado o problema, e o contexto que gera as necessidades e objetivos de um projeto, é possível elencar os procedimentos que identificam a adoção da cross fertilization como método de trabalho. Embora seja constatada certa flexibilidade nestas ações, pode-se afirmar que se trata do seguinte: iniciar a busca de dados, informações e conceitos pesquisando em áreas do conhecimento, que não aquela na qual está inserido o projeto; fazer associações entre elementos distintos - e de áreas diversas - para estabelecer analogias; identificar critérios que permitam comparar aspectos análogos das áreas distintas; ponderar e selecionar os critérios mais adequados para viabilizar a transferência de conhecimento implícito (de sentido ou significado) ou explícito (de fabricação, processo ou tecnologia); experimentar novas competências e gerar alternativas para solucionar o problema com base nos critérios selecionados; e finalmente, identificar a melhor solução. Trata-se, portanto, garante Conti (2007), de uma prática metodológica para a busca do novo e uma fonte de conhecimento inesgotável, por ser exclusivamente alimentada pela curiosidade da pesquisa. 


\subsection{Relatos da prática}

O que significa projetar uma peça de mobiliário como se fosse um terno ou vestir um móvel como se fosse um corpo? Ou ainda, projetar um objeto que serve para decorar o corpo e a casa ao mesmo tempo?

Estas provocações constituíram-se como principal objetivo de um workshop realizado no Politecnico di Milano com estudantes e professores do Laboratório de Síntese Final do Curso de Laurea Magistrale in Design de Sistema Moda, financiado pela Etro. Trata-se de uma empresa italiana de tecidos para vestuário, reconhecida mundialmente pela utilização de materiais têxteis de origem étnica; há alguns anos ela transferiu a habilidade e os conhecimentos das técnicas de produção de roupas aos móveis. O workshop baseou-se na ampliação do universo deste tipo de atividade, na tentativa de transferir ao setor de acessórios para a casa, as notáveis competências da empresa na execução das técnicas de alfaiataria aplicadas ao vestuário e ao mobiliário. Desenvolveram-se vários produtos em torno da proposta, que ilustram situações nas quais adotou-se a cross fertilization como método de trabalho.

O projeto Regina utilizou resíduos de materiais têxteis: previa-se que todos os tecidos fossem agrupados sobrepostos, depois enrolados e em seguida cortados transversalmente para obter um assento. A Figura 1 mostra o protótipo da poltrona Regina e o produto em exposição na Mostra ETRO Le Trame Avvolgenti, realizada no showroom da empresa, por ocasião do Salone del Mobile 2006, em Milão.
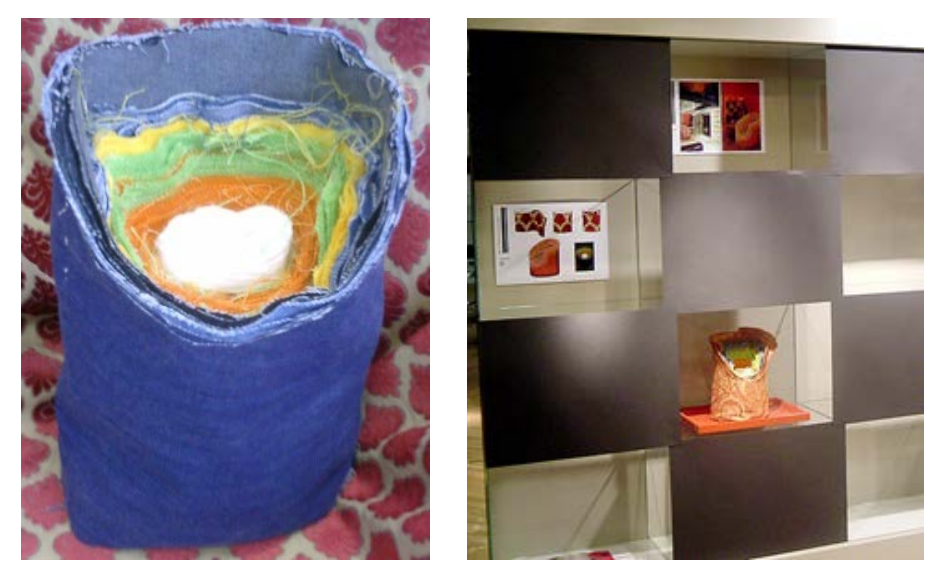

Figura 1 - Poltrona Regina

Fonte: Elaborado pelos autores, com base na pesquisa realizada.

Kittavolgi era um projeto também focado no aproveitamento do descarte dos materiais têxteis mas diferenciava-se do anterior porque incluía a proposta de um kit para a restauração de móveis velhos. Os resíduos, depois de separados e remontados, costurados uns aos outros, eram cortados em longas tiras (Figura 2 ). 

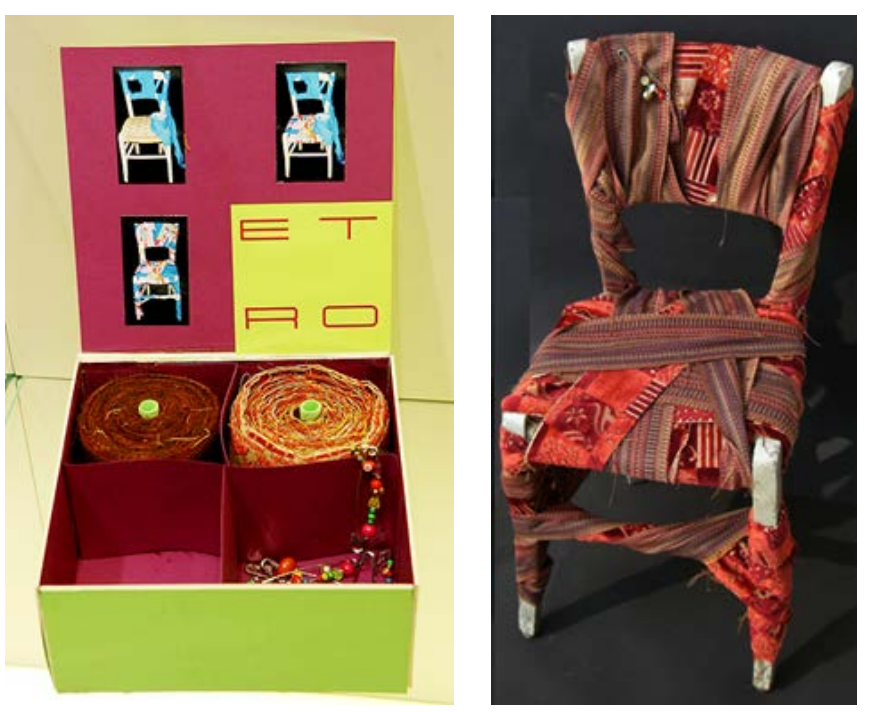

Figura 2 - Kit Kittavolgi e proposta de cadeira revestida com os resíduos Fonte: Elaborado pelos autores, com base na pesquisa realizada.

Luci Rosse (Figura 3) relembrava, por um lado, o mundo das luminárias penduradas na parte externa dos restaurantes chineses, por outro, remetia a um significado mais ousado e audacioso vinculado ao imaginário do mundo dos adultos. 0 projeto consistia na criação de alguns lustres realizados em tecido e pensados para representar uma variedade de silhuetas de saias femininas. Para que o produto continuasse a lidar com o elemento surpresa, foi projetado de modo que, olhando sob o lustre, o espectador não via a lâmpada mas sim, uma outra peça do vestuário.

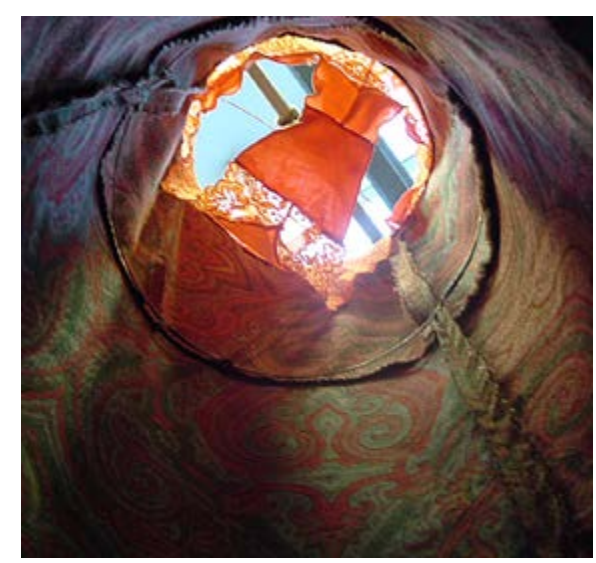

Figura 3 - Protótipos do projeto Luci Rosse

Fonte: Elaborado pelos autores, com base na pesquisa realizada.

O projeto Alosnem (Figura 4), que significa prateleira (mensola) escrito ao contrário, ocupava-se da análise das estruturas das estantes clássicas em madeira, para a partir daí descobrir como executar as prateleiras somente com o uso de tecidos e obter uma estrutura que permitisse a montagem de uma estante. 


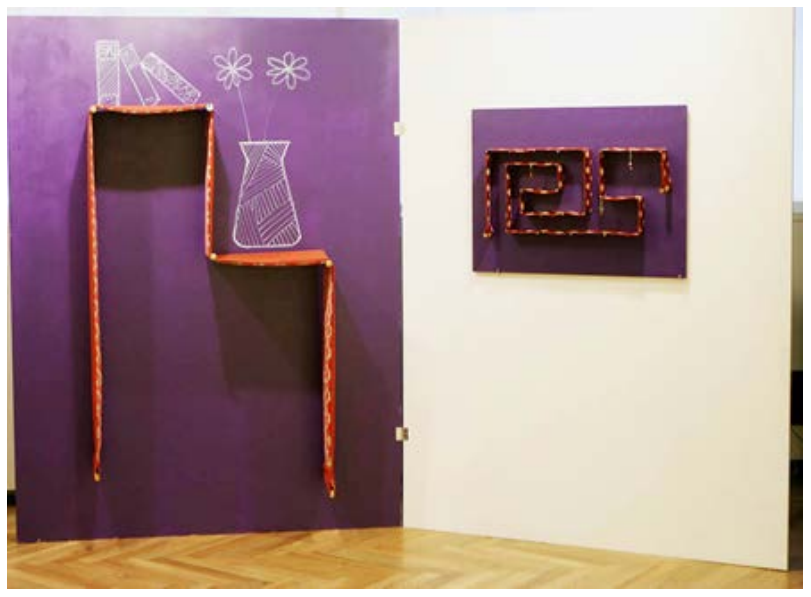

Figura 4 - Protótipos e modelos do projeto Alosnem

Fonte: Elaborado pelos autores, com base na pesquisa realizada.

No contexto da mesma metodologia, um outro panorama pode ser traçado, no qual também é pertinente pensar esses processos experimentais de design e educação. Em um workshop de quatro dias, intitulado Performative Geometries, realizado em 2009 na Aristotle University Thessaloniki, componentes e materiais usados no design de moda foram propostos como mecanismos principais para a exploração do espaço.

Vyzoviti (2010) sugere um novo conceito para o material têxtil: propõe que ele seja percebido como um dispositivo relativo, que engloba tanto a superfície quanto o ornamento, gera padrões, e faz alusão à performance como um sistema de resposta. Assim, é possível ver o material como ferramenta e suporte para experimentações: para ações de dobrar, enrolar, torcer e cortar; para geração de formas; para ser determinante do espaço; para ser impulsionado pelo movimento; para se submeter à percepção dos sentidos.

Nessa condição, se visto pelo viés do design de moda ou da arquitetura, é apropriado afirmar que os materiais operam como meios para que se encontrem formas vestíveis - ou na visão de Vyzoviti (2010), formas arquitetônicas - que mesmo experimentadas e realizadas de maneira análoga, estejam em concordância com os princípios essenciais da morfogênese. Animadas pelo corpo humano, essas superfícies, impregnadas de rica diversidade, tornam-se aptas para realizarem performances suportadas por este corpo em movimento.

No workshop, afirma Agkathidis (2010), inicialmente foram analisados produtos criados por designers renomados, na tentativa de investigar os efeitos materiais e espaciais do uso dos tecidos. Posteriormente deveriam transformar os componentes analisados em novos sistemas aptos a serem vivenciados - explorados e alterados pelos próprios corpos, enquanto vestidos nas estruturas criadas.

A exploração dos têxteis, seus princípios geométricos ocultos e o desenvolvimento sistemático de suas características físicas e espaciais foram essenciais para o processo. Schillig (2010) argumenta que experiências como esta criam expectativas acerca de um novo e aberto conceito de arquitetura, no qual o corpo humano é a força operacional. Agkathidis (2010) complementa que por meio de sua interação, o corpo introduz um processo cinemático e coreográfico de manipulação 
geométrica, capaz de produzir uma grande quantidade de efeitos. Corpo e material fundem-se em um sistema combinado, que envolve sensações e opera como um gerador de detalhes e texturas no espaço.

Referindo-se a proposta e aos resultados do workshop enfatiza-se a grande oportunidade de especular sobre uma nova construção para um objeto arquitetônico, partindo de materiais que não fazem parte do universo do arquiteto.

Tal abordagem reveste-se de grande importância e reafirma a validade das experiências que não consideram uma área disciplinar de modo isolado mas sim a zona de intersecção que pode ser gerada entre uma e outra.

\section{CONCLUSÃO}

A análise das intersecções que se estabelecem entre os distintos campos comprova que é dentro destas áreas de fronteira que são ativadas de fato as dinâmicas que facilitam os processos de inovação significativos. O pensamento projetual denota uma troca contínua e um diálogo constante entre conhecimentos diversos.

A inovação é para o design e para a arquitetura fonte de constante mudança e lugar para a experimentação. É cada vez mais evidente que se esteja passando da projetação de um produto à projetação de um processo que, em seguida, trará possíveis repercussões para o sistema de produtos, sejam eles físicos ou intangíveis. Assim, as atividades típicas dos setores passam a se integrar e a configurar cenários aqueles lugares nos quais se realiza o cruzamento de experiências e se efetiva, de fato, a cross fertilization.

A ideia de projeto, hoje, coincide com objetos, sistemas e sinais que regulam as relações entre os seres humanos e seu contexto. Neste panorama, evidencia-se a importância da cross fertilization aplicada ao processo de desenvolvimento de produtos, especialmente nas fases iniciais de definição de estratégias ampliando-se a abrangência da inovação.

\section{AGRADECIMENTOS}

À Fundação Araucária que apoia o desenvolvimento desta pesquisa com o fomento à primeira autora por meio da bolsa de Produtividade em Pesquisa e Desenvolvimento Tecnológico.

\section{REFERÊNCIAS}

AGKATHIDIS, Asterios. Analog digital design processes. In: AGKATHIDIS, Asterios; SCHILLIG, Gabi (Ed.). Performative Geometries: transforming textile techniques. Amsterdam: BIS, 2010. p. 146-151.

AGKATHIDIS, Asterios; SCHILLIG, Gabi (Ed.). Performative Geometries: transforming textile techniques. Amsterdam: BIS, 2010.

CONTI, Giovanni Maria. 2007. Moda e cultura del progetto industriale: cross fertilization per i'nnovazione. Tesi (Dottorato in Disegno Industriale e Comunicazione Multimediale, XIX ciclo) - Scuola di Dottorato, Politecnico di Milano, Milano (Italia). 
CONTI, Giovanni Maria.2008. "Moda e cultura de projeto industrial: hibridação entre saberes complexos" In PIRES, Dorotéia Baduy (Org.). Design de Moda: olhares diversos. pp. 219-230. Estação das Letras e Cores. São Paulo (Brasil).

GIESEL, Aline; SOUZA, Patricia de Mello. The correlation between thermal comfort in buildings and fashion products In: WORLD CONGRESS ON ERGONOMICS, 18, 2012, Recife. Anais... Recife: IOS Press, 2012. p. 5561-5563.

HERKENHOFF, Paulo. Louise Bourgeois. The unmentionable, blades, fabrics and fashion. In: BRAND, Jan; TEUNISSEN, José (Ed.). Fashion and imagination about clothes and art. Arnhem: ArtEZ, 2009. p. 234-247.

HODGE, Brooke (Org.). Skin + bones: parallel practices in fashion and architecture. Londres: Thames \& Hudson, 2007.

KINNEY, Leila W.. Fashion and fabrication in modern architecture. In: BRAND, Jan; TEUNISSEN, José (Ed.). Fashion and imagination about clothes and art. Arnhem: ArtEZ, 2009. p.248-259.

KÖHLER, Carl. História do vestuário. São Paulo: Martins Fontes, 2005.

LAKATOS, E. M.; MARCONI, M. A. Técnicas de pesquisa: planejamento e execução de pesquisas, amostragens e técnicas de pesquisa, elaboração, análise e interpretação de dados. São Paulo: Atlas, 2011.

MELLO, Marcia Maria Couto. Modas, arquiteturas e cidades: interfaces, conexões e interferências. 2010. Tese (Doutorado em Arquitetura) - Universidade Federal da Bahia, Salvador, 2010.

PIRES, Dorotéia Baduy (Org.). Design de Moda: olhares diversos. São Paulo: Estação das Letras e Cores, 2008.

QUINN, Bradley. The fashion of architecture. New York : Berg Oxford, 2003.

. The fashion of architecture. In: BRAND, Jan; TEUNISSEN, José (Ed.). Fashion and imagination about clothes and art. Arnhem: ArtEZ, 2009. p. 260-275.

SALTZMAN, Andrea. El cuerpo diseñado: sobre la forma en el proyecto de la vestimenta. Buenos Aires: Paidós, 2004.

. O design vivo. In: PIRES, Dorotéia Baduy (Org.). Design de Moda: olhares diversos. São Paulo: Estação das Letras e Cores, 2008. p.305-318.

SCHILLIG, Gabi. Elasticity of space. In: AGKATHIDIS, Asterios; SCHILLIG, Gabi (Ed.). Performative Geometries: transforming textile techniques. Amsterdam: BIS, 2010. p. 8-13.

SEIVEWRIGHT, Simon. Research and design. Lausanne: AVA, 2007.

SILVA, Lizandra. Aspectos teóricos do conforto sob o ponto de vista da ergonomia. In: CONGRESSO BRASILEIRO DE ERGONOMIA, 16., 2010, Rio de Janeiro. Anais... Rio de Janeiro: ABERGO, 2010.

SOUZA, Patrícia de Mello. A modelagem tridimensional como implemento do processo do desenvolvimento do produto de moda. 2006. Dissertação (Mestrado em Desenho Industrial) - Faculdade de Arquitetura, Artes e Comunicação, Universidade Estadual Paulista, Bauru, 2006. 
SOUZA, Patrícia de Mello. 2013. Estratégias de construção para estruturas têxteis vestíveis. Tese (Doutorado em Design) - Faculdade de Arquitetura, Artes e Comunicação, Universidade Estadual Paulista, Bauru. (Brasil).

TREVISAN M.; PEGORARO M..2007. Retail design. Franco Angeli, Milano (Italia) VYZOVITI, Sophia. Methodological shifts: the textile as retro-novel paradigm. In: AGKATHIDIS, Asterios; SCHILLIG, Gabi (Ed.). Performative Geometries: transforming textile techniques. Amsterdam: BIS, 2010. p. 108-113.

Supersurfaces: folding as a method of generating forms for architecture, products and fashion. Amsterdam: BIS, 2008. 